\title{
Measurement of Sr/Ca Ratio in Bones as a Temperature Indicator
}

\author{
P. R. dos Santos, N. Added, M. A. Rizzutto, J. H. Aburaya, and M. D. L. Barbosa \\ Departamento de Física Nuclear, Instituto de Física, Universidade de São Paulo,
} Caixa Postal 66318, CEP 05315-970, São Paulo, SP, Brazil

\section{Received on 18 March, 2006}

\begin{abstract}
The purpose of this work is to correlate $\mathrm{Sr} / \mathrm{Ca}$ ratio with internal body temperature from teeth and bones. Results obtained in exploratory measurements using human, bovine and swine teeth indicated some relation between temperature and $\mathrm{Sr} / \mathrm{Ca}$ ratio, but no other parameters, as feeding habits that certainly has some influence over $\mathrm{Sr} / \mathrm{Ca}$ ratio, were controlled. In this work, to eliminate feeding effects, we decided to compare $\mathrm{Sr} / \mathrm{Ca}$ ratio of bones from some individual. The first bones irradiated were from a crocodile (Caiman Yacare), which regulates the internal body temperature by the temperature of its surroundings. The pieces irradiated were from the crocodile's tail, vertebral column and leg. To quantify $\mathrm{Sr}$ and $\mathrm{Ca}$ a $2.4 \mathrm{MeV}$ proton beam was used in PIXE beam line at LAMFI - USP. Emitted X-rays were collected using a Si(Li) detector (150eV @ $6.4 \mathrm{KeV})$. First results show that the bones closer to the heart have a lower $\mathrm{Sr} / \mathrm{Ca}$ ratio.
\end{abstract}

Keywords: Sr/Ca ratio; Internal body temperature; Teeth and bones

\section{INTRODUCTION}

Analysis of the $\mathrm{Sr} / \mathrm{Ca}$ ratio in aragonite $\left(\mathrm{CaCO}_{3}\right)$ from sea shells and coral skeletons was used for precise measurement of sea water temperature $[1,2]$. Coral skeletons grows in the same way as trees and the difference in $\mathrm{Sr} / \mathrm{Ca}$ ratio along the growing direction is related to the temperature of the water surroundings at the respective time (Fig. 1).

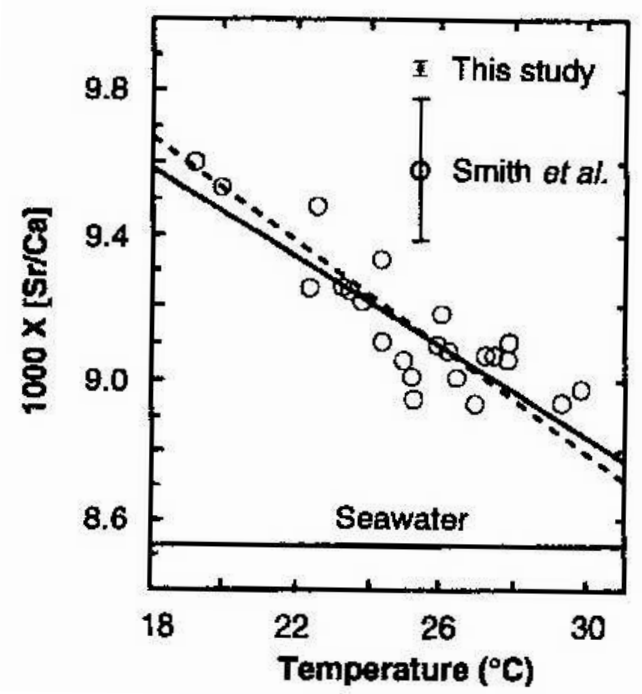

FIG. 1: $\mathrm{Sr} / \mathrm{Ca}$ relation of coral skeletons against sea temperature. Fig. from [1].

In this way, $\mathrm{Sr} / \mathrm{Ca}$ ratio from sea shells and coral skeletons can be used as historical data of sea water temperature. The results show great agreement if compared to satellite data, Fig. (2).

So, the initial idea of our studies was to relate $\mathrm{Sr} / \mathrm{Ca}$ ratio of human, bovine and swine teeth with body respective temperature. Teeth, as bones, are mainly composed by another calcium crystal called hydroxiapatite $\left(\mathrm{Ca}_{10}\left(\mathrm{PO}_{4}\right)_{6}(\mathrm{OH})_{2}\right)$. Each

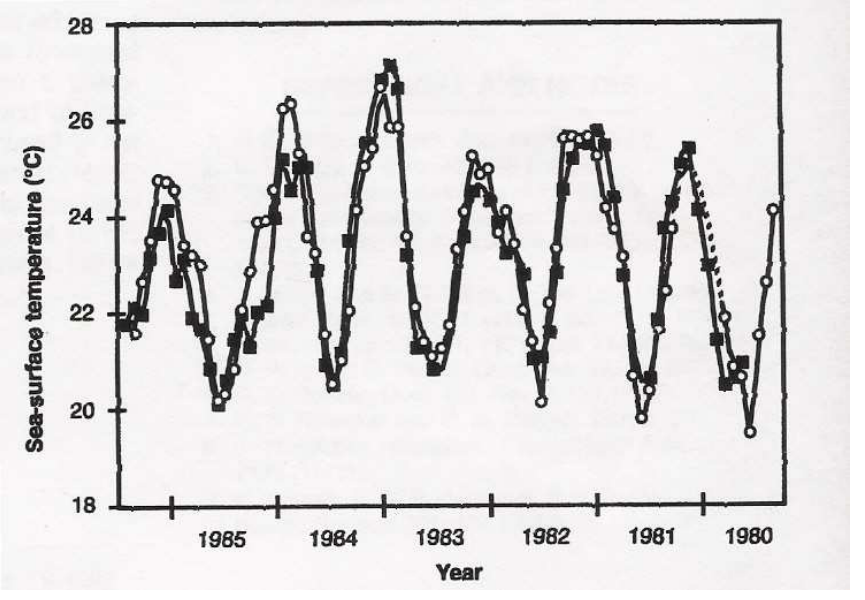

FIG. 2: Sea water temperature from $\mathrm{Sr} / \mathrm{Ca}$ ratio from coral sketeton results and satellite data along the years. Fig. from [2].

species has a different body temperature. For humans, its average is $36,9(6){ }^{\circ} \mathrm{C}$ [3], for bovine, temperature average is $39,0(5){ }^{\circ} \mathrm{C}$ and for swine, its average is $39,0(10){ }^{\circ} \mathrm{C}$ [4]. The average values for $\mathrm{Sr} / \mathrm{Ca}$ resulted of irradiation of 30 samples (enamel and dentine) can be seen in Figs. 3 and 4.

It can be observed that the angular coefficient from data prescuted in $\mathrm{Sr} / \mathrm{Ca} \times \mathrm{T}$ plots from Figs. 1, 3 and 4 have opposite signs. These results show that probably strontium quantity in hydroxyapatite is dependent of some other parameters that can hide temperature effects.

One of these parameters is feeding habits $[5,6]$, that wasn't controlled in our samples. To eliminate feeding effects it was decided to compare $\mathrm{Sr} / \mathrm{Ca}$ of bones from the same individual.

For every vertebrate, independent of its thermoregulation pattern (endothermic or ectothermic), there is a variation of temperature along the body. Usually the warmest parts are the parts closer to the heart and to the brain, and the coldest are the extremities, as feet [7].

It was chosen, for first irradiation, a crocodile (Caiman 


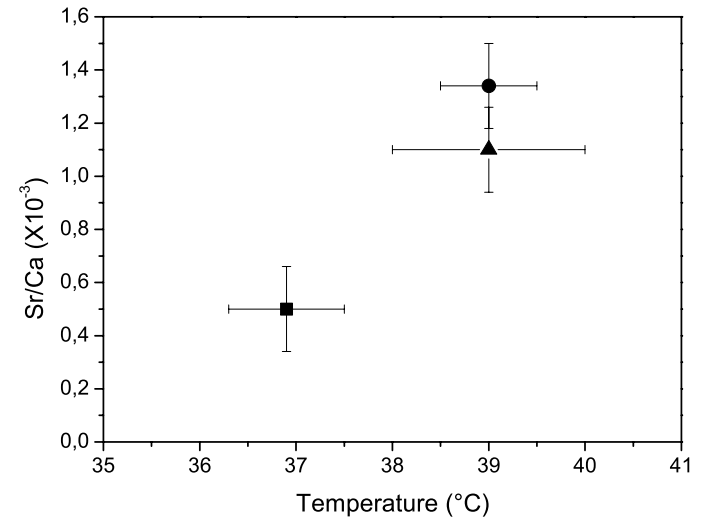

FIG. 3: Average of $\mathrm{Sr} / \mathrm{Ca}\left(\times 10^{-3}\right)$ ratio for dentine irradiation against body temperature. Human data is represented by a circle, bovine data by a square and swine data by a triangle.

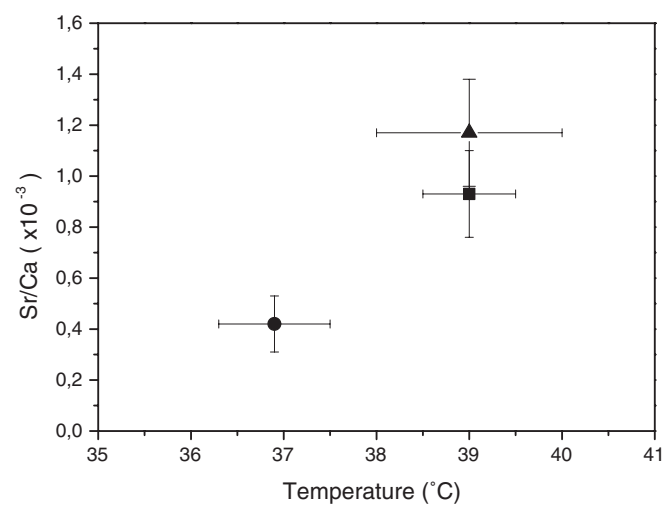

FIG. 4: Average of $\mathrm{Sr} / \mathrm{Ca}\left(\times 10^{-3}\right)$ ratio for enamel irradiation against body temperature. Human data is represented by a circle, bovine data by a square and swine data by a triangle.

Yacare), which specie regulates its body temperature uptaken heat from the environment (ectothermy) and probably has a bigger range between the warmest and the coldest parts of the body than an endothermic animal.

\section{EXPERIMENTAL FACILITY}

Regular PIXE analysis were performed at the Laboratory for Material Analysis by Ion Beams at University of São Paulo (LAMFI-USP), using a $2.4 \mathrm{MeV}$ proton beam. The pieces irradiated were a bone from one leg, three from the different points of vertebral column (see figure 5) and two from the tail.

The samples were fixed in carbon targets and mounted in a multiposition target holder at the center of the PIXE vacuum

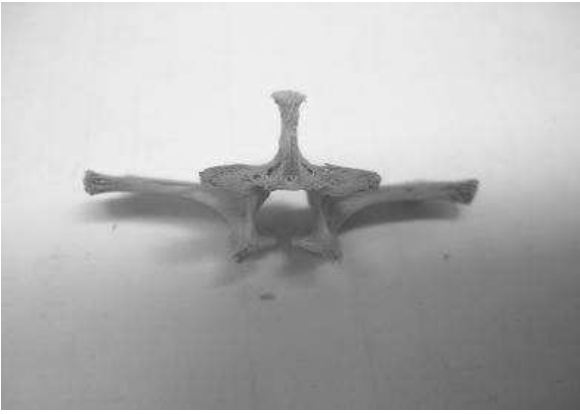

FIG. 5: One of the bones irradiated from the spinal column.

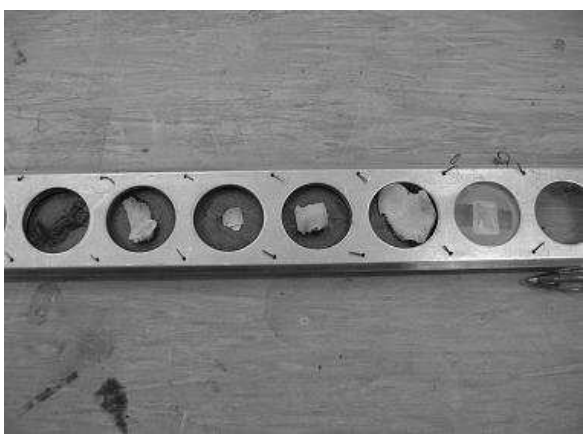

FIG. 6: Bones ready for irradiation in the multiposition target holder.

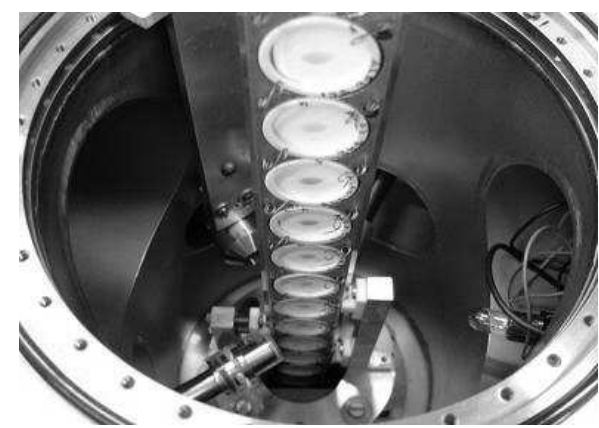

FIG. 7: Multiposition target holder in the center of the PIXE chamber.

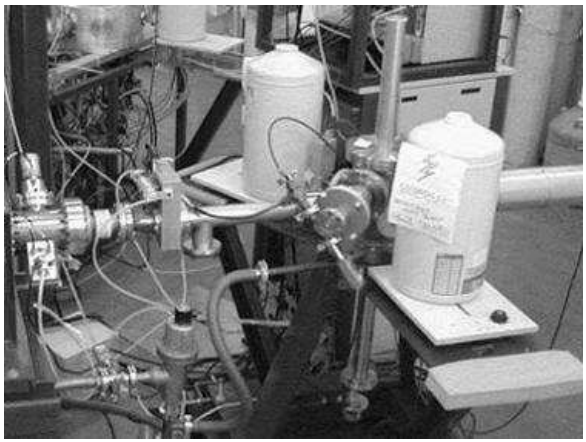

FIG. 8: External view of the experimental setup showing $\mathrm{Si}(\mathrm{Li})$ detectors and vacuum chamber. 


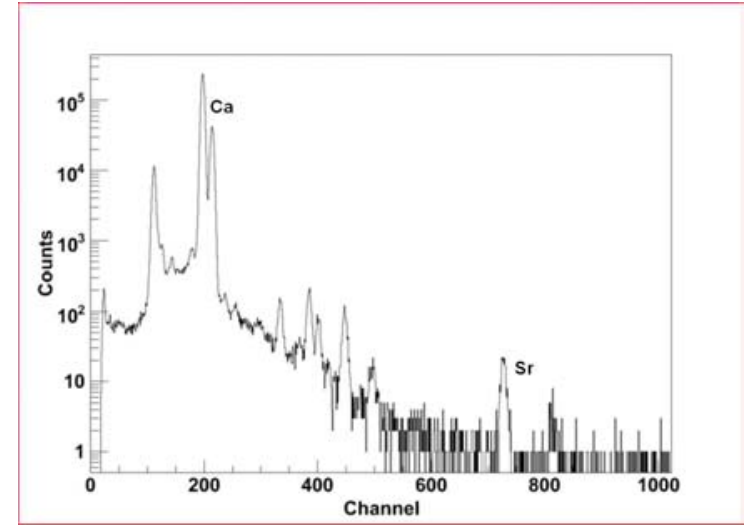

FIG. 9: Energy espectrum from one of the irradiations using ROOT code.

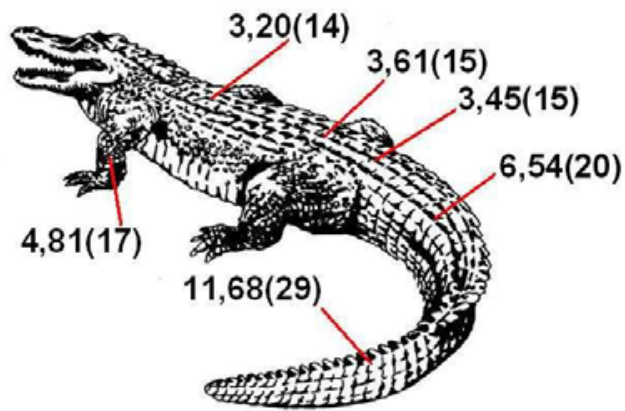

FIG. 10: Schematic draw of $\mathrm{Sr} / \mathrm{Ca}$ quantities in crocodile bones. chamber as it can be seen in Figs. 6 and 7.

Two $\mathrm{Si}(\mathrm{Li})$ detectors with resolutions around $150 \mathrm{eV}$ for 6.4 $\mathrm{KeV}$ were used to collect the X-rays emitted by the samples. An external view of the experimental setup is shown in Fig. 8.

\section{PRELIMINARY RESULTS}

All energy spectra were analyzed using ROOT code [8]. In Fig. 9 a typical X-ray energy spectrum can be seen.

The quantities of strontium and calcium were obtained integrating the respective peak areas and normalizing them by the number of incident particles (charge), thin film PIXE yields [9] and correction factors for thick target [10]. Uncertainties for $\mathrm{Sr}$ and $\mathrm{Ca}$ were evaluated using statistical considerations.

The results of preliminary irradiations can be seen in Fig. 10. It's not difficult to see that there is a tendency of a lower $\mathrm{Sr} / \mathrm{Ca}$ ratio closer to the heart region and a higher $\mathrm{Sr} / \mathrm{Ca}$ ratio in the extremities, as we expected.

\section{Acknowledgments}

We would like to thank Dr. Manfredo H. Tabaknics for ideas and discussions. We also would like to thank FAPESP and CNPq for financial support.
[1] R. W. Buddemeier, R. C. Redale, and J. E. Houce, Science 204, 404 (1979);

[2] J. Warren Beck et al., Science 257, 644 (1992);

[3] "Human Temperature" http://www.icb.ufmg.br/ neurofib/Engenharia/ Temperatura/processos\%20biologicos.htm (2005);

[4] "Animal Temperature" http://www.saudeanimal.com.br/artigo97_ print.htm (2005);

[5] M. Sponheimer et al., Journal of Human Evolutions 48, 147 (2005);
[6] J. H. Burton and L. E. Wright, American Journal of Physical Anthropology 96, 273 (1995);

[7] Reese E. Barrick and William J. Showers, Science 265, 222 (1994);

[8] Root code source: http://root.cern.ch/ (2005);

[9] M. H. Tabacniks, CLCPIXE.xls (2005). Private communication (2005).

[10] J. H. Aburaya, Padronização de análises PIXE de amostras sólidas em alvos espessos, MS Dissertation, Instituto de Física, Universidade de São Paulo, Brasil (2005). 